\title{
Cardiomyopathy associated with congenital heart disease
}

\author{
Abraham Shem-Tov, Victor Deutsch, Joseph H. Yahini, and Henry N. Neufeld \\ From the Heart Institute, and Department of Diagnostic Radiology, \\ Tel-Hashomer Government Hospital and Tel-Aviv University Medical School, Israel
}

Thirteen patients with congenital heart disease associated with cardiomyopathy, all proven by right and/or left heart study or necropsy are described. The presence of cardiomyopathy was established before the age of 12 in ro cases, 4 of them before 2 years. In 2 instances, familial occurrence of cardiomyopathy was observed. In 3 cases, cardiomyopathy was an integral part of the parachute mitral valve complex. The association of cardiomyopathy with congenital heart disease, its familial occurrence, its discovery in childhood and infancy, and its frequent appearance in the parachute mitral valve complex all favour a congenital origin of some forms of cardiomyopathy, and not a coincidental occurrence of two conditions.

It is felt that this combination is not as rare as is thought. The presence of cardiomyopathy associated with congenital heart disease should be suspected whenever the latter cannot explain one or more of the following: the presence of heart failure, evidence of left ventricular hypertrophy in the electrocardiogram and/or chest $\mathrm{x}$-ray, or the suggestive carotid pulse pressure curve and/or apex cardiogram.

The aetiology of most forms of cardiomyopathy remains unknown. There is evidence that in some instances the condition may be familial (Brent et al., 1960), and in others acquired (Brachfeld and Gorlin, 1959; Brock, 1957). Furthermore, the presence of additional congenital heart disease in some patients does point towards a congenital aetiology of the condition (Somerville and McDonald, 1968).

In reviewing the published material, we have found less than 40 documented cases of cardiomyopathy associated with congenital heart disease. The present article deals with 13 additional patients displaying this combination and supplies further support for the possibility that in some instances cardiomyopathy may be congenital in origin. Furthermore, in the light of the above-mentioned experience, the clinical clues suggesting the presence of associated cardiomyopathy in patients with congenital heart disease are commented upon.

\section{Patients and methods}

This study comprises 13 patients: 12 with obstructive and I with nonobstructive cardiomyopathy. The sex, age, and associated congenital heart disease are shown in Table I. The diagnosis of Received 3I December 1970. congenital heart defects was made clinically and confirmed in each case by right and/or left heart studies and by operation and/or necropsy (Table I). Mitral insufficiency or right ventricular infundibular stenosis which could represent an integral part of the cardiomyopathy were not considered as associated defects. The criterion for the diagnosis of obstructive cardiomyopathy was the demonstration by a direct pullback tracing of a systolic pressure gradient between the cavity and the outflow tract of the left ventricle and the typical cardioangiographic features of obstructive cardiomyopathy. In 2 patients (Cases 5 and 9), the systolic pressure gradient between the left ventricular cavity and outflow tract could not be measured for technical reasons, but the cardioangiographic features were diagnostic. Right heart studies alone were performed in 3 patients (Cases IO, II, and I3); left heart study alone in one (Case 4) and both right and left heart studies in 8 (Cases I, 2, 3, 5, 6, 7, 8, and 9). An operation was performed in 2 patients (Cases 3 and 13) and necropsy in 3 (Cases II, 12, and 13). In Case 12 there were no studies and the diagnosis was established at necropsy. Heart disease was discovered at birth in 9 patients (Cases 2, 3, 5, 6, 7, 9, 11, 12, and 13); before the age of 3 months in 3 patients (Cases $I$, 8 , and IO), and at the age of II years (as part of a family survey) in I (Case 4).

Phonocardiograms, apex cardiograms, and carotid and jugular pulse pressure curves were registered in 8 patients (Cases $\mathrm{I}, 2,3,5,6$, IO, II, and 13 ). 
TABLE I Thirteen patients with cardiomyopathy associated with congenital heart disease (age of discovery, data of right and left heart studies, and associated defects)

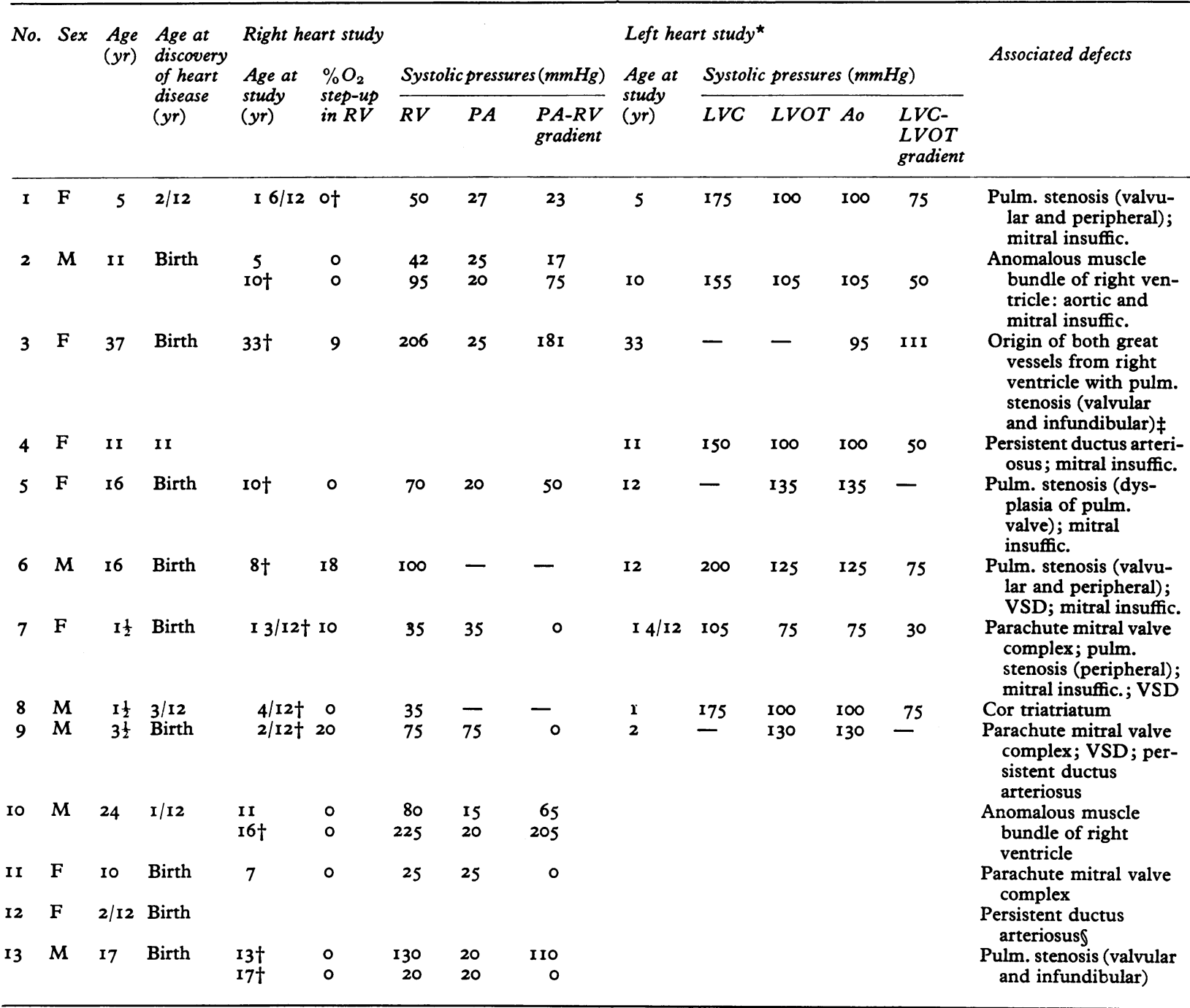

$\mathrm{RV}=$ right ventricle; $\mathrm{PA}=$ pulmonary artery; $\mathrm{Ao}=$ aorta $\mathrm{LVC}=$ left ventricular cavity $; \mathrm{LVOT}=$ left ventricular outflow tract $; \mathrm{VSD}=\mathrm{ven}-$ tricular septal defect.

* All patients with left heart catheterization underwent left ventriculography.

† Patient underwent selective right ventriculography.

$¥$ Diagnosis confirmed during complete correction.

$\$$ Diagnosis confirmed at necropsy.

\section{Case reports}

Case I A 5-year-old girl from normal pregnancy and delivery. Family history was negative. She was first examined at the age of 2 months because of growth failure and dyspnoea and a tentative diagnosis of ventricular septal defect was made. At the age of 18 months, she was slightly underdeveloped; a grade 3 pansystolic murmur along the left sternal border, radiating to the apex and axilla, and a grade $\mathrm{I}-2$ rumbling diastolic murmur at the apex were heard. The electrocardiogram showed left axis deviation with counterclockwise rotation of the QRS in the frontal plane and biventricular hypertrophy (Fig. IA). The chest $x$-ray showed heart enlargement, particularly of the left ventricle. Because of these findings, the diagnosis of ventricular septal defect of the persistent common AV canal type with mitral insufficiency was made. At this age, right heart catheterization and selective right ventriculography were performed (Fig. 3B). No shunt was found; right ventricular systolic pressure was 50 $\mathrm{mmHg}$ and main pulmonary artery pressure was 


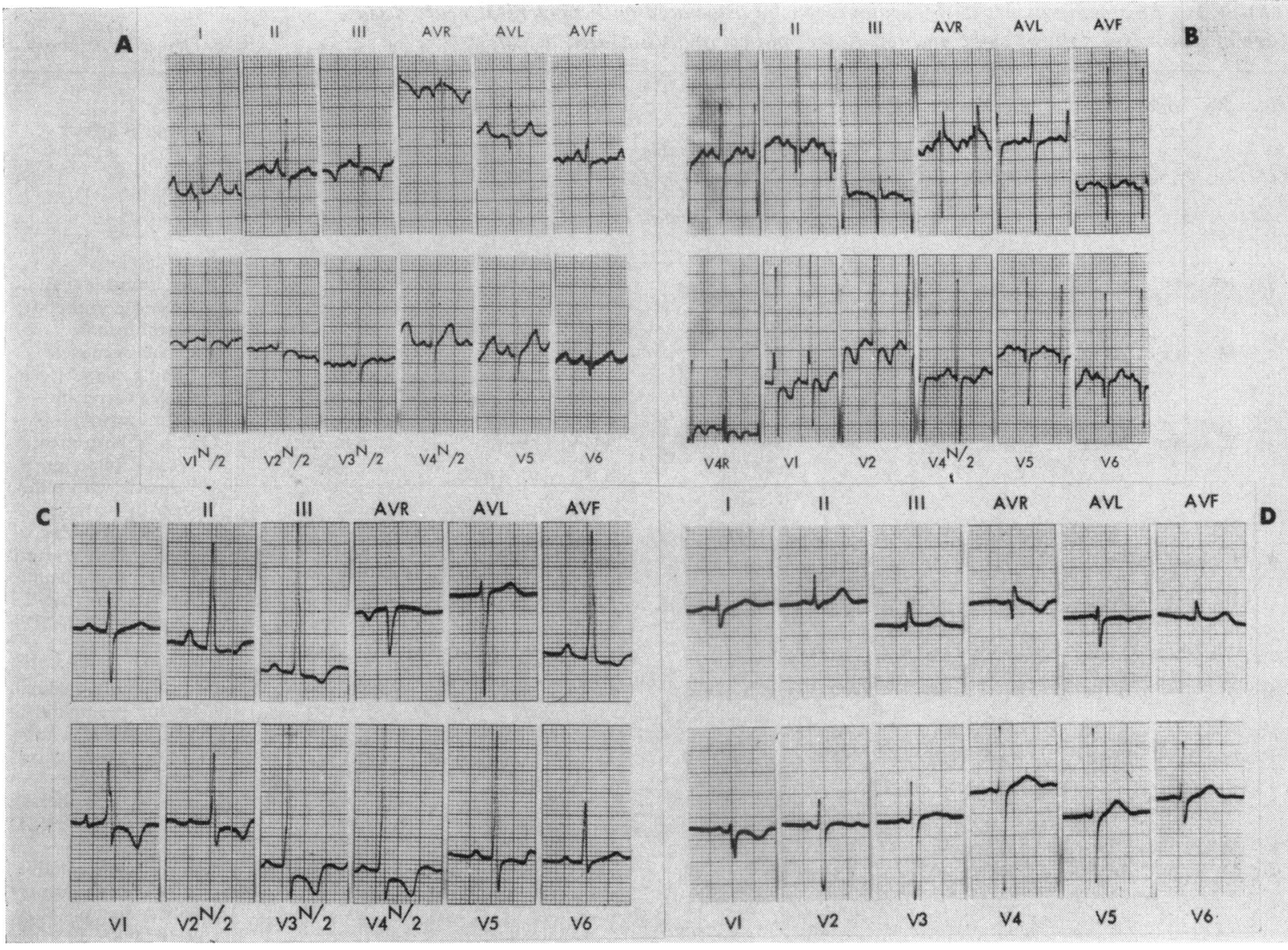

FIG. I ( $A, B, C$, and D.) Electrocardiograms of Cases $I, 9$, Io, and 4, respectively. $A, B$, and $C$ show biventricular hypertrophy. $D$ is within normal limits.

$27 \mathrm{mmHg}$ with a systolic gradient of $23 \mathrm{mmHg}$ (Table I). On cardioangiography the diagnosis of mild pulmonary stenosis was confirmed together with peripheral pulmonary artery stenosis. Associated obstructive cardiomyopathy was suspected from the presence of left ventricular asymmetric hypertrophy and contraction. This suspicion was further strengthened by phonocardiography and carotid pulse pressure curve and apex cardiogram (Fig. 2A). Left ventriculography was performed at the age of 5, which confirmed the diagnosis of obstructive cardiomyopathy: left ventricular systolic pressure was $175 \mathrm{mmHg}$; aortic systolic pressure was 100, with a systolic pressure gradient of $75 \mathrm{mmHg}$ between the cavity and the outflow tract of the left ventricle (Table I). The cardioangiographic findings were typical of obstructive cardiomyopathy (Fig. 3A) with mitral insufficiency.

Comment This 5-year-old girl, whose chief complaint was dyspnoea, suffered from mild pulmonary stenosis, valvular and peripheral, associated with mitral insufficiency and obstructive cardio- myopathy confirmed by right and left heart studies. In retrospect, it appears that the diagnosis of associated cardiomyopathy could have been made at the age of 2 months if cardiac catheterization and selective cardioangiography had been performed at that time.

Case 2 An I I-year-old boy from normal pregnancy and delivery. Family history was negative. Heart disease was known since birth. At the age of 5 years the clinical diagnosis of ventricular septal defect was made, based on the presence of left ventricular heave, thrill, and grade 4 pansystolic murmur near the sternal border, a grade 2 rumbling diastolic murmur at the apex, the electrocardiogram showing left ventricular hypertrophy, and chest $x$-ray showing left heart enlargement. Right heart catheterization performed at that time showed no shunt, a right ventricular systolic pressure of $42 \mathrm{mmHg}$, and pulmonary artery systolic pressure of $25 \mathrm{mmHg}$ with a gradient of $17 \mathrm{mmHg}$ (Table $\mathrm{I}$ ). The diagnosis of mild pulmonary infundibular stenosis was made. Since there was no evidence of ventricular septal defect, 
the presence of an apical diastolic murmur, deep $Q$ waves in III, aVF, and $V_{3}$ to V6 in the electrocardiogram, and left ventricular enlargement on $x$-rays pointed to the presence of associated obstructive cardiomyopathy. This suspicion was further enhanced by the phonocardiogram, typical carotid pulse pressure curve, and apex cardiogram. At the age of ro, the patient's chief complaint was dyspnoea. A repeated right heart catheterization with selective right and left ventriculography were performed (Fig. 4), together with retrograde aortography. Main pulmonary artery and right ventricular outflow tract systolic pressures were $20 \mathrm{mmHg}$, while the systolic pressure in the right ventricular cavity was $95 \mathrm{mmHg}$ (Table I). The systolic pressure in the left ventricular cavity was $155 \mathrm{mmHg}$ while the pressure in the outflow tract and the aorta was $105 \mathrm{mmHg}$ (Table I and Fig. 5A). The diagnosis of anomalous muscle bundle of the right ventricle associated with obstructive cardiomyopathy, mitral insufficiency, and aortic insufficiency was made.

Comment This I I-year-old boy had an anomalous muscle bundle of the right ventricle associated with obstructive cardiomyopathy, mitral insufficiency, and aortic insufficiency, diagnosed by right and left heart studies. Heart disease was known from birth. The diagnosis of subpulmonary stenosis was made at the age of 5 by right heart catheterization, but the physical findings, the electrocardiogram, and chest $x$-ray raised the possibility of associated obstructive cardiomyopathy at that time.

Case 3 A 37-year-old woman with no abnormal birth history. Family history was negative. Heart disease was known since birth. At the age of 14 , tetralogy of Fallot was diagnosed on cardioangiocardiography and a Blalock shunt operation performed. In reviewing the cardioangiographic findings on follow-up examination, it was found that she was actually suffering from origin of both great vessels from the right ventricle with pulmonary stenosis. Phonocardiogram, carotid pulse curve, and apex cardiogram raised the possibility of associated obstructive cardiomyopathy. These diagnoses were later confirmed at the age of 33 by preoperative catheterization (Table I) and cardioangiography. The right ventricular systolic pressure was $206 \mathrm{mmHg}$, the pulmonary artery systolic pressure $25 \mathrm{mmHg}$, and the aortic systolic pressure $95 \mathrm{mmHg}$, with a systolic gradient of $18 \mathrm{r}$ $\mathrm{mmHg}$ across the pulmonary and III $\mathrm{mmHg}$ across the aortic valve. Cardioangiography visualized pulmonary stenosis, valvular and subvalvular, and severe muscular subaortic stenosis. A ventricular septal defect was also found. Total correction was done.

Comment A 37-year-old woman with origin of both great vessels from the right ventricle with pulmonary stenosis and associated muscular subaortic stenosis. The diagnosis was confirmed by right and left heart studies and at operation.

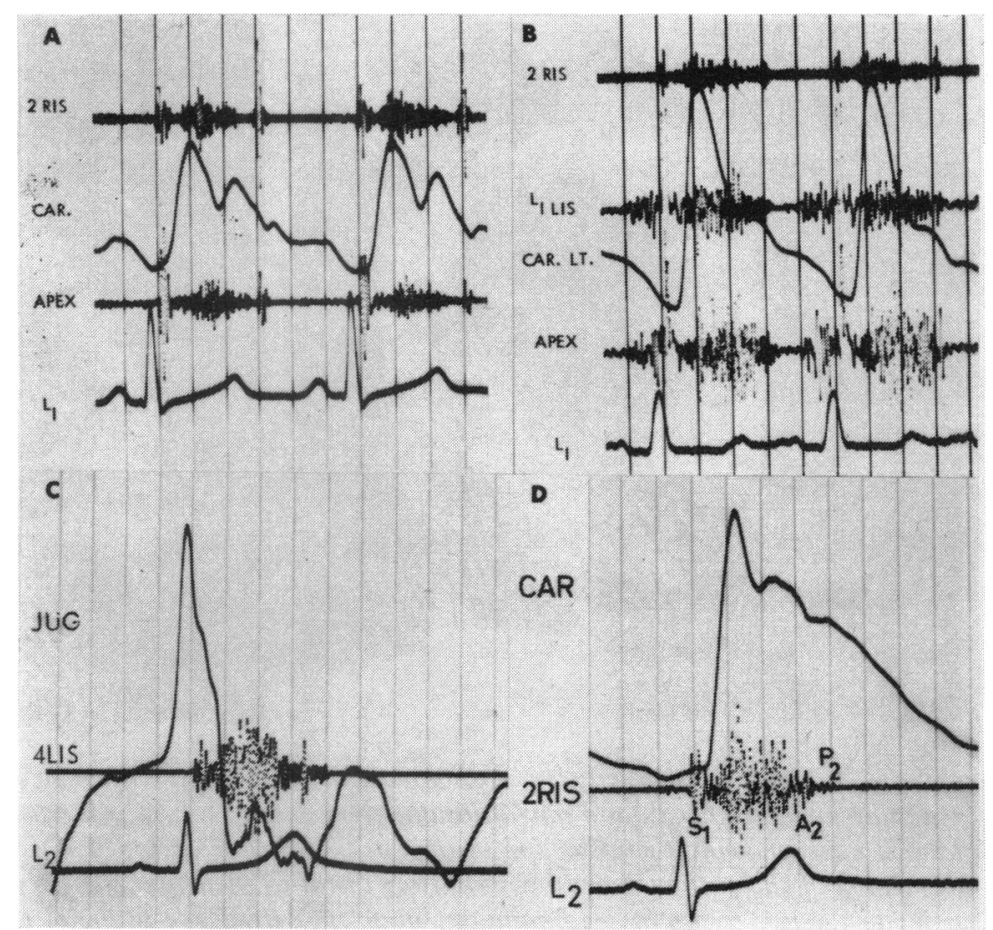

FIG. 2 ( $A, B, C$, and D.) Simultaneous electrocardiogram, phonocardiogram, and indirect jugular ( $\mathcal{F} U G)$ and carotid $(C A R)$ pulse pressure curves of Cases $I, I I$, and 6, respectively. The carotid curve in $A$ (Case I) shows the characteristic features of obstructive cardiomyopathy: a short upstroke time, a midsystolic dip, and a late systolic rise. At the apex, a pansystolic murmur of mitral regurgitation is present. The carotid curve in $B$ (Case II) shows a short upstroke time but without a tidal wave; in addition, a pansystolic and a presystolic murmur are best seen at the apex. $C$ and $D$ (Case 6) jugular and carotid curves, respectively. A prominent $A$ wave is seen in the jugular curve. The carotid curve reveals the typical short upstroke time, midsystolic dip, and late systolic rise. In addition, a pansystolic murmur with midsystolic accentuation and splitting of the second sound $\left(A_{2}-P_{2}\right)$ with $a$ weak $P_{2}$ are present.

Case 4 An II-year-old girl, the product of normal pregnancy and delivery. She is from a Bedouin family of 5 children. Four of the 5 sibs had heart disease. Our patient, who is asymptomatic, has a continuous murmur at the pulmonary area and a grade 2-3 ejection systolic murmur near the sternum. The second sound was normally split. The electrocardiogram was normal (Fig. ID); the chest $x$-ray revealed a degree of cardiomegaly unexpected with a small persistent ductus arteriosus. 


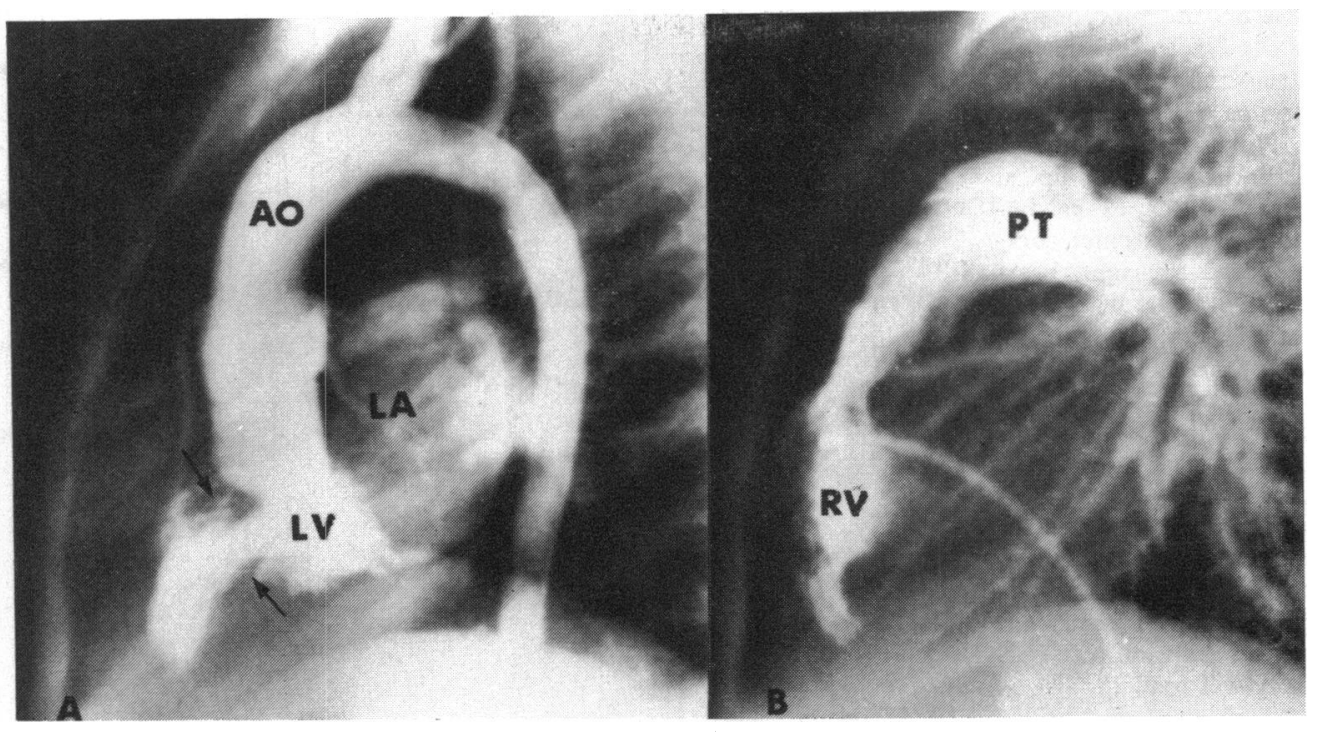

FIG. 3 ( $A$ and B.) Obstructive cardiomyopathy associated with mild pulmonary stenosis, valvular and peripheral, and mitral insufficiency (Case I). ' $A$ ' is a selective left ventriculogram, lateral view, showing the distortion of the left ventricular cavity $(L V)$. The characteristic dilatation of the outflow tract during systole distal to the obstruction is well seen. The two arrows point to the two hypertrophied papillary muscles. Retrograde filling of the left atrium $(L A)$ due to mitral regurgitation is also seen. ' $B$ ' is a right ventriculogram, lateral view, showing the thickened pulmonary valve and the poststenotic dilatation of the pulmonary trunk (PT).

Left ventriculography performed at the age of II revealed a systolic gradient of $50 \mathrm{mmHg}$ between the cavity and the outflow tract of the left ventricle (Table I). Cardioangiography confirmed the presence of persistent ductus arteriosus and revealed a typical picture of obstructive cardiomyopathy (Fig. 6). A male sib of 12 had obstructive cardiomyopathy, confirmed by left ventriculography. Another sib, a girl of 4, had persistent ductus arteriosus. A 20-month-old brother had persistent ductus arteriosus with peripheral pulmonary artery stenosis. In both of these last two patients, the diagnosis was confirmed by right heart catheterization and cardioangiography and their ducti were ligated. Nevertheless, a harsh systolic murmur was heard along the left sternal border after operation, and the possibility of associated cardiomyopathy cannot be ruled out.

Comment This I I-year-old girl has persistent ductus arteriosus associated with obstructive cardiomyopathy and mitral insufficiency. The diagnosis was confirmed by left ventriculography. The family history of heart disease is of particular interest.

Case 5 A 16-year-old girl from normal pregnancy and delivery complained mainly of dyspnoea on effort. Heart disease was known from birth. At the age of ro the diagnosis of valvular pulmonary stenosis was made, based on the presence of a systolic thrill, ejection systolic sound, and a grade 4 ejection systolic murmur at the pulmon- ary area, with wide splitting of the second sound and weak pulmonary compound. The presence of left ventricular hypertrophy on the electrocardiogram suggested an associated left heart lesion. Right heart catheterization and selective right ventriculography performed at the age of 10 confirmed the diagnosis of pulmonary valvular stenosis. Right ventricular systolic pressure was 70 $\mathrm{mmHg}$ and pulmonary artery systolic pressure $20 \mathrm{mmHg}$ (Table I). On cardioangiography, the cusps of the pulmonary valve were thickened suggesting dysplasia of the pulmonary valve. In addition, the interventricular septum bulged into the right ventricle and there was left ventricular outflow tract obstruction in the laevogram suggesting an associated obstructive cardiomyopathy. Phonocardiogram, carotid pulse pressure curve, and apex cardiogram also enhanced this suspicion. At the age of 12 , left ventriculography was performed with the catheter positioned in the left ventricular outflow tract during injection. The systolic pressure gradient could not be measured (Table I). The left ventriculogram was typical of obstructive cardiomyopathy: the outflow tract was in the form of an inverted cone during diastole, with extreme asymmetrical hypertrophy of the left ventricle. The region of the obstruction was also visualized. Moreover, retrograde filling of the left atrium was present.

Comment This 16-year-old girl suffers from congenital valvular pulmonary stenosis, possibly from dysplasia of the pulmonary valve, associated with 


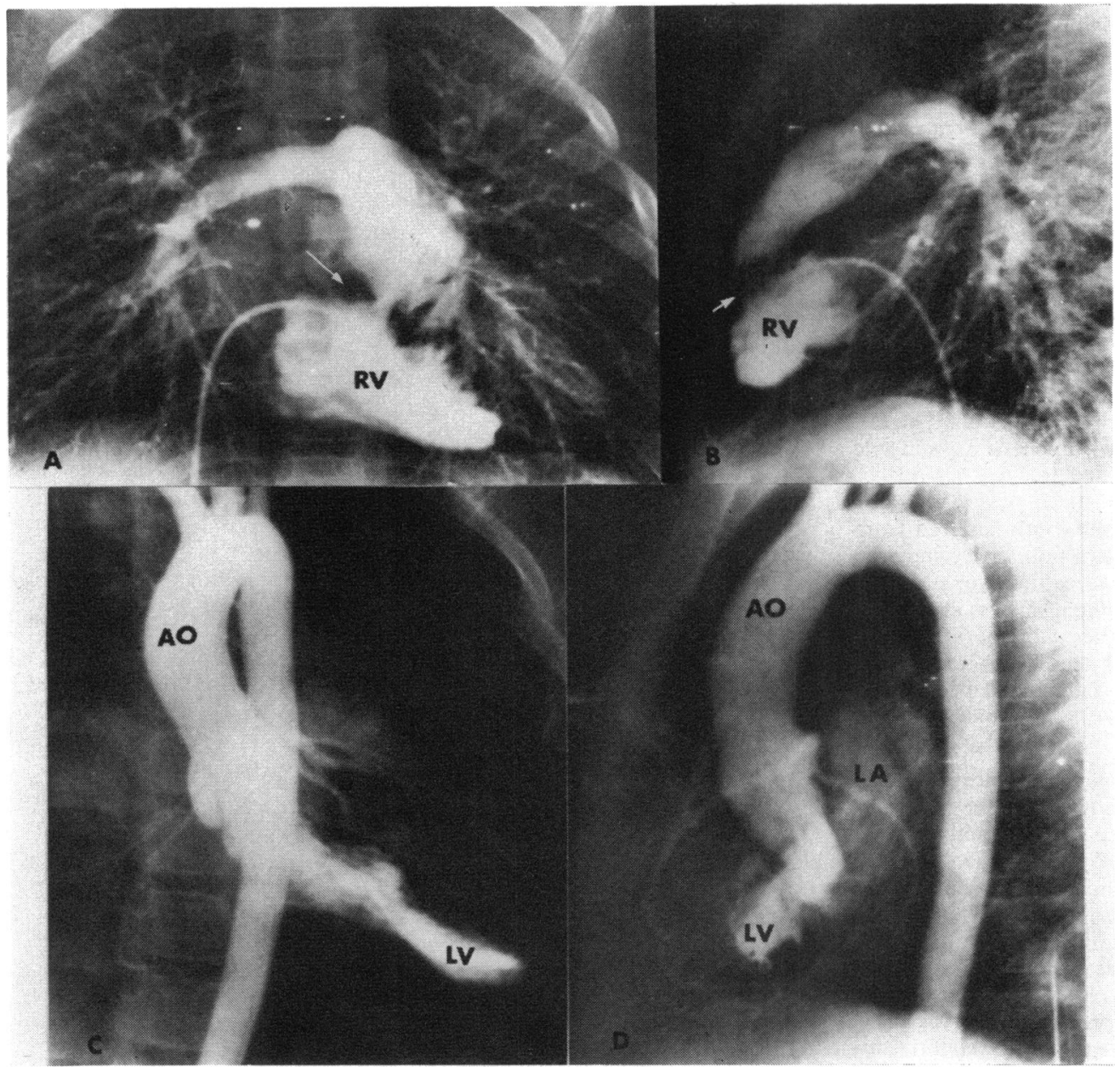

FIG. 4 ( $A, B, C$, and D.) Obstructive cardiomyopathy associated with anomalous muscle bundle of the right ventricle, mitral insufficiency, and aortic insufficiency (Case 2). $A$ and $B$, selective right ventriculogram, frontal and lateral views, respectively, showing in particular the anomalous muscle bundle at the junction of the sinus part and the outflow tract of the right ventricle (arrows). In $C$ and $D$, selective left ventriculogram, frontal and lateral views, respectively, the characteristic distortion of the left ventricular cavity is seen. A retrograde filling of the left atrium $(L A)$ due to mitral insufficiency is best visualized in $D$.

obstructive cardiomyopathy and mitral insufficiency. The associated obstructive cardiomyopathy was suspected from the electrocardiogram displaying left ventricular hypertrophy in the presence of clinical findings of pulmonary stenosis. The diagnoses were confirmed by right and left heart studies.

Case 6 A 16-year-old youth from normal pregnancy and delivery. Family history was negative. Heart disease has been known since birth. Exertional dyspnoea and cyanosis appeared at the age of 7 years. At that time a clinical diagnosis of ventricular septal defect with pulmonary stenosis with bidirectional, but predominant left-to-right shunt, was made. The physical findings were mild cyano- sis, a systolic thrill with a grade 4 pansystolic murmur to the left of the sternum with midsystolic accentuation, and wide splitting of the second sound with weak pulmonary component. There was biventricular hypertrophy on the electrocardiogram and cardiomegaly with increased vascularity on chest $x$-ray. Right heart catheterization and selective right ventriculography at the age of 8 confirmed the clinical diagnosis. There was absent right superior vena cava; the catheter entered through a persistent left superior vena cava into the coronary sinus, right atrium, and right ventricle. The pulmonary artery could not be entered. Right ventricular systolic pressure was 100 mmHg. There was a step-up in $\mathrm{O}_{2}$ saturation in the right ventricle of 18 per cent (Table $\mathrm{I}$ ). 
Selective right cardioangiography revealed the presence of a pulmonary stenosis, valvular and peripheral. The aorta filled from the right ventricle. At the age of 9 he was admitted in mild heart failure. Examination disclosed increased left ventricular heave and progression of heart size on $x$-rays. These features suggested the presence of associated cardiomyopathy. Jugular and carotid pulse pressure curve and apex cardiogram enhanced this impression (Fig. $2 \mathrm{C}$ and D). At the age of $\mathrm{I2}$ selective left ventriculography was performed which confirmed the presence of obstructive cardiomyopathy and initial insufficiency. The systolic pressure in the cavity of the left ventricle was $200 \mathrm{mmHg}$, while those of the outflow tract and the aorta were $125 \mathrm{mmHg}$ (Fig. 5C). The left ventriculogram revealed conspicuous asymmetric hypertrophy of the left ventricle.

Comment This I6-year-old youth suffered from ventricular septal defect with pulmonary stenosis, associated with obstructive cardiomyopathy and mitral insufficiency. The diagnosis was confirmed by right and left heart studies. Obstructive cardiomyopathy was suspected from the unexpected appearance of mild heart failure and progressive increase in heart size.

Case 7 A I $\frac{1}{2}$-year-old girl from normal pregnancy and delivery was known to suffer from congenital heart disease since birth. Family history was negative. On physical examination she was found to be dyspnoeic. There was a systolic thrill, a grade 4 pansystolic murmur near the sternum and a grade 2 rumbling diastolic murmur at the apex, the second sound was normally split, and the femoral pulses were weak. The electrocardiogram revealed biventricular hypertrophy and the chest $x$-ray moderate cardiomegaly with slightly increased vascularity. The clinical diagnosis of ventricular septal defect with mild coarctation of the aorta was made. On right heart catheterization and selective right ventriculography the pulmonary artery wedge pressure was normal; there was a is $\mathrm{mmHg}$ systolic gradient between the left and main pulmonary artery; no gradient was found between the main pulmonary artery and the right ventricle (Table I). A step-up of ro per cent in $\mathrm{O}_{2}$ saturation was found in the right ventricle. Selective right cardioangiography confirmed the presence of peripheral pulmonary artery stenosis and the laevogram raised the possibility of associated obstructive cardiomyopathy. Left ventriculography performed one month later confirmed the diagnosis of obstructive cardiomyopathy (Fig. 7 and Table I). A systolic gradient of $30 \mathrm{mmHg}$ was found between the cavity and the outflow tract of the left ventricle.

Comment This I $\frac{1}{2}$-year-old girl suffered from mild coarctation of the aorta, subaortic stenosis of the muscular type, ventricular septal defect, peripheral pulmonary artery stenosis, and mitral insufficiency (parachute mitral valve complex). Obstructive cardiomyopathy was an integral part of this complex.

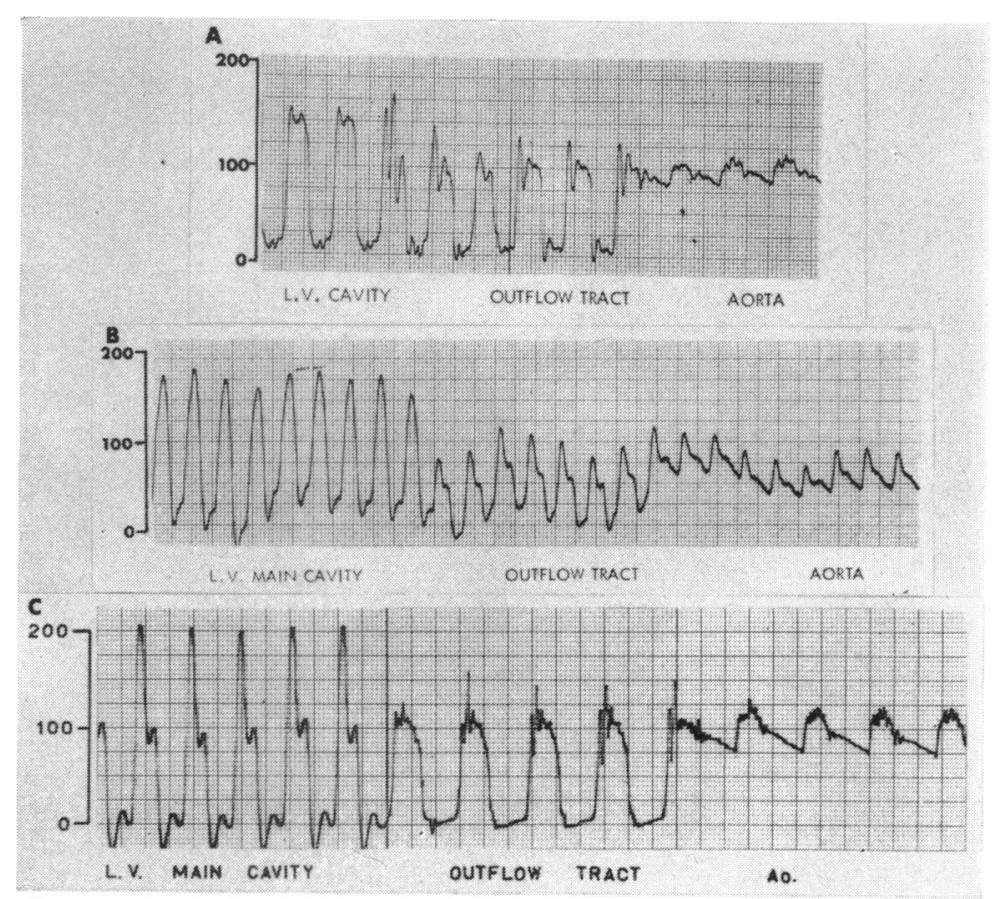

FIg. 5 ( $A, B$, and $C$.) Pressure tracings recorded continuously as the catheter was withdrawn from the left ventricular cavity through the left ventricular outflow tract and into the ascending aorta (Case 2, 8, and 6, respectively). There is a systolic pressure gradient between the cavity and the outflow tract of the left ventricle without further gradient across the aortic valve.

Case 8 A I $\frac{1}{2}$-year-old boy from normal pregnancy and delivery. Family history was negative. He was first examined at the age of 3 months because of frequent respiratory infections, and heart disease was discovered. At the age of 4 months, cardiomyopathy was suspected from the presence of heart failure, an ejection grade 2-3 systolic murmur near the sternum, biventricular hypertrophy on electrocardiogram, and globally enlarged heart on $x$-ray. Right heart catheterization and selective right ventriculography were then performed (Table $\mathbf{r}$ ). The right ventricular pressure was slightly raised $(35 \mathrm{mmHg})$; the laevophase of the cardioangiography revealed cor triatriatum and raised the possibility of associated obstructive cardiomyopathy. This was confirmed at the age of I year by left ventriculography: the systolic pressure in the cavity of the left ventricle was 175 $\mathrm{mmHg}$ while it was $100 \mathrm{mmHg}$ in both the outflow tract and the aorta (Table I and Fig. 5B). There was an extremely asymmetrical hypertrophied left ventricle.

Comment This $\mathrm{I} \frac{1}{2}$-year-old boy suffers from cor triatriatum associated with obstructive cardio- 


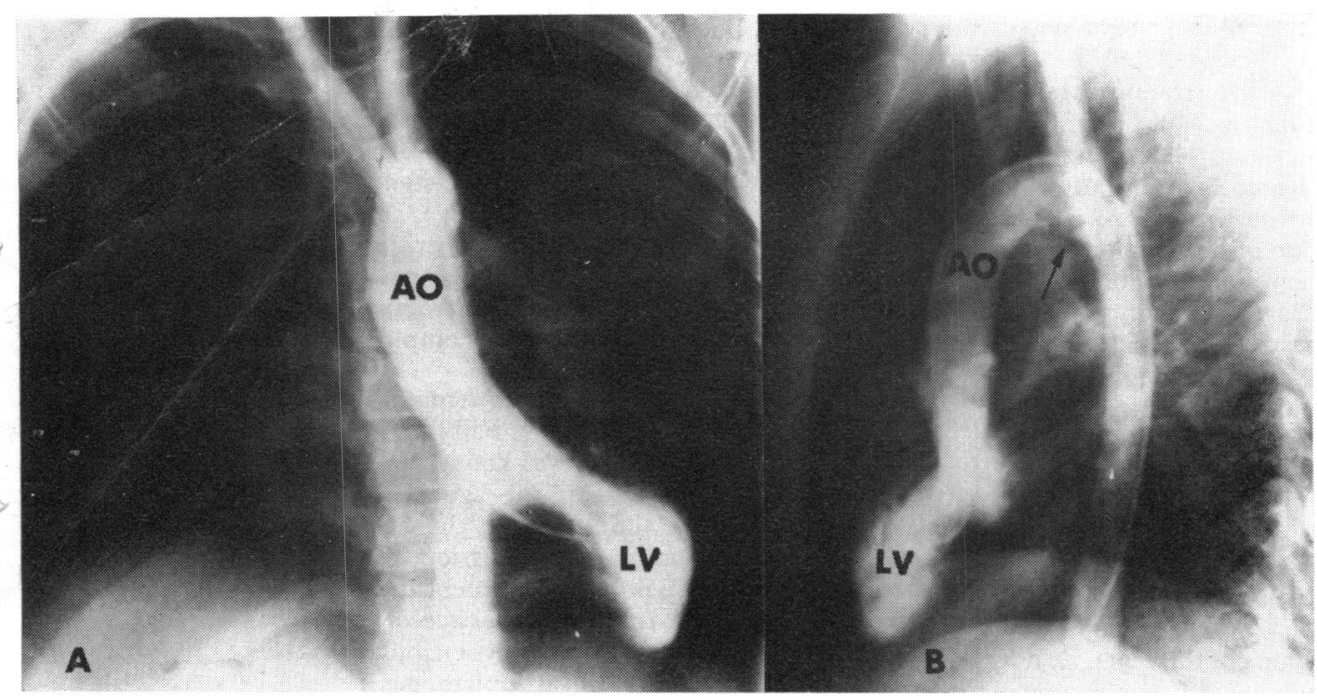

a. FIG. 6 ( $A$ and B.) Obstructive cardiomyopathy associated with patent ductus arteriosus and mitral insufficiency in Case 4. $A$ and $B$, left ventriculogram, frontal and lateral views respectively, showing the asymmetrical contraction of the left ventricle $(L V)$. Filling of the pulmonary artery through the persistent ductus arteriosus (arrow) is seen in B.

myopathy. The diagnosis of cor triatriatum was made at the age of 4 months. Associated obstructive cardiomyopathy was suspected at this age from the clinical findings and the laevophase of cardioangiography. Obstructive cardiomyopathy was confirmed by selective left ventriculography at the age of I year.

Case 9 A $3 \frac{1}{2}$-year-old boy from normal pregnancy and delivery has been under our care since birth on account of repeated attacks of pulmonary oedema. Family history was negative. Heart disease has been known since birth. On the second day of birth he presented the clinical picture of 'hypoplastic left heart syndrome'. At the age of 2 months, on physical examination femoral pulses were absent, a grade 2 pansystolic murmur at the left sternal border, a grade 2-3 ejective systolic murmur at the pulmonary area, and a grade 2 rumbling diastolic murmur at the apex were heard.

The second sound was narrowly split with accentuation of the pulmonary component. The electrocardiogram showed biventricular hypertrophy (Fig. IB), and the chest $x$-ray revealed cardiomegaly with increased lung vascularity. Right heart catheterization and selective cardioangiography were performed at this age (Table $\mathrm{I}$ ). The catheter passed through a persistent ductus arteriosus. The pulmonary artery wedge pressure was very high (mean $26 \mathrm{mmHg}$ ), and the pulmonary artery systolic pressure was $75 \mathrm{mmHg}$; the systolic pressure in the descending aorta was $88 \mathrm{mmHg}$; there was a step-up in $\mathrm{O}_{2}$ saturation in the right ventricle of 20 per cent; coarctation of the aorta and left ventricular hypertrophy were visualized on the laevophase. The diagnosis of ventricular septal defect, coarctation of the aorta, persistent ductus arteriosus, and pulmonary hypertension was made. At the age of 19 months, retrograde aortography was performed. The systolic pressure in the left subclavian artery was $130 \mathrm{mmHg}$. Coarctation of the aorta was well visualized. On follow-up examination at the age of 2 years the possibility of parachute mitral valve complex was entertained and selective left ventriculography performed (Table r), with injection of contrast material in the left ventricular outflow tract. No systolic pressure gradient could be obtained. However, the left ventriculogram revealed myocardial hypertrophy and subaortic obstruction.

Comment This $3 \frac{1}{2}$-year-old boy has parachute mitral valve complex with coarctation of the aorta and subaortic stenosis of the muscular type. In addition, there is an associated ventricular septal defect and persistent ductus arteriosus. The diagnosis was confirmed by right and left heart studies. This case provides further evidence that obstructive cardiomyopathy is an integral part of this complex.

Case 10 A 24-year-old man from normal pregnancy and delivery. Heart disease has been known since the age of $I$ month. At the age of II, the clinical diagnosis of pulmonary stenosis was made from the presence of right ventricular uplift, systolic thrill and a grade 5-6 ejection systolic murmur to the left of the sternal border, wide splitting of the second sound with a weak pulmonary component, right ventricular hypertrophy on the electrocardiogram, and heart enlargement on $x$-rays. However, the presence of associated left ventricular hypertrophy on the electrocardiogram 
and left heart enlargement on chest $x$-rays suggested the presence of an associated left heart lesion. At right heart catheterization right ventricular systolic pressure was $80 \mathrm{mmHg}$ and the pulmonary artery systolic pressure I5 $\mathrm{mmHg}$ (Table I). The diagnosis of infundibular stenosis was made from the withdrawal pressure curve and the low region of obstruction seen on fluoroscopy. Phonocardiography, carotid pressure curve, and apex cardiogram enhanced the suspicion of associated obstructive cardiomyopathy. At the age of 16 a repeat right heart catheterization (Table I) and selective right ventriculography were made. The electrocardiogram at that time revealed extreme biventricular hypertrophy (Fig. IC); the right ventricular systolic pressure was $225 \mathrm{mmHg}$ and the pulmonary artery systolic pressure was $20 \mathrm{mmHg}$. Selective right cardioangiography showed anomalous muscle bundle of the right ventricle and the laevophase pictures showed extreme bulging of the ventricular septum into the left ventricular cavity, confirming the clinical diagnosis of associated obstructive cardiomyopathy.

Comment This 24-year-old man had an anomalous muscle bundie of the right ventricle associated with obstructive cardiomyopathy. Though heart disease was discovered shortly after birth, the above combination was diagnosed only at the age of 16 years, after detailed investigation.

Case II A ro-year-old girl from normal pregnancy and delivery. Family history was negative. Heart disease was known from birth. In addition, she suffered from coeliac disease with severe hypochromic anaemia which necessitated numerous periods in hospital. At the age of 7 parachute mitral valve complex was suspected from the presence of weak femoral pulses, heart enlargement, a grade 3 pansystolic and presystolic murmur at the apex, an ejection murmur near the left sternal border, and signs of biventricular and left atrial hypertrophy on the electrocardiogram and $x$-rays. The phonocardiogram, carotid pressure curve, and apex cardiogram enhanced the clinical diagnosis of associated subaortic stenosis (Fig. 2B). Right heart catheterization performed at the age of 7 revealed normal pressure in the lesser circulation (Table $\mathrm{I}$ ). At the age of ro the child died in heart failure. Necropsy findings confirmed the clinical diagnosis of parachute mitral valve complex. The heart was moderately enlarged; the left ventricle was hypertrophied, its wall thickness being $17 \mathrm{~mm}$. There was a single hypertrophied papillary muscle to the mitral valve. The interventricular septum was disproportionately thickened $I .5 \mathrm{~cm}$ below the aortic valve and was covered by a fibrous layer encroaching on the outflow tract of the left ventricle and constituting the subaortic obstruction. The left atrium was dilated, its wall thickness being $3 \mathrm{~mm}$. There was a circular membrane, constituting a stenotic ring $2-3 \mathrm{~mm}$ above the mitral valve annulus; this stenosis was not very significant. In addition, mild coarctation of the aorta, distal to the origin of the left subclavian artery, was found. Both right atrium and ventricle were normal.

Comment This Io-year-old girl suffered from the complete form of parachute mitral valve complex, i.e. with coarctation of the aorta, subaortic stenosis, parachute deformity of the mitral valve, and supravalvular stenotic ring within the left atrium. This diagnosis was confirmed by necropsy. Again, this case provides added evidence that obstructive cardiomyopathy is an integral part of the complex.

Case 12 A 2-month-old baby girl, premature, from normal pregnancy and delivery. Family history was negative. Heart disease was known from birth. Heart failure appeared at the age of $\mathrm{I}_{2} \frac{1}{2}$ months, which required admittance to the hospital at the age of 2 months. On admission, she was critically ill. The diagnosis of persistent ductus arteriosus was made from the presence of a continuous murmur, biventricular hypertrophy on the electrocardiogram, and heart enlargement on $x$-rays. The child died 3 days later. Necropsy findings revealed obstructive cardiomyopathy in addition to the persistent ductus arteriosus. There was moderate heart enlargement. The heart weight was $40 \mathrm{~g}$, the left ventricle was hypertrophied with a wall thickness of $\mathrm{I} \mathrm{cm}$, the interventricular septum was very hypertrophied and bulging into the left ventricular outflow tract, and the right ventricular wall thickness was $0 \cdot 4 \mathrm{~cm}$. Bilateral haemorrhagic bronchopneumonia with multiple abscess formation were also present.

Comment This 2-month-old baby presented the clinical picture of persistent ductus arteriosus with heart failure. Associated obstructive cardiomyopathy was found at necropsy.

Case 13 A 17-year-old youth of normal pregnancy and delivery. Heart disease was known from birth. A sib, age 22, suffers from nonobstructive cardiomyopathy discovered at the time of his enrolment in the army. At the age of 13, the patient complained of dyspnoea. The clinical diagnosis of pulmonary stenosis was made based on the presence of a systolic thrill, a grade 4 ejection systolic murmur at the left sternal border and wide splitting of the second sound with weak pulmonary component, right heart hypertrophy on electrocardiogram, and heart enlargement on chest $x$-ray. Right heart catheterization was performed at that time (Table I). The pulmonary artery systolic pressure was $20 \mathrm{mmHg}$, right ventricular systolic pressure was $130 \mathrm{mmHg}$, and a transitional zone of systolic pressure of 63 $\mathrm{mmHg}$ at the level of the outflow tract of the right ventricle was found. The diagnosis of pulmonary stenosis, valvular and infundibular, was made and the patient was referred for operation. Pulmonary valvotomy and infundibular resection were performed. During operation, the surgeon noticed an enlarged left ventricle and an associated left heart lesion was suspected. Three years after the operation, heart failure appeared. A repeat right heart catheterization showed no systolic gradient between the pulmonary artery and the right ven- 
tricle (Table I). The patient died at the age of 17 after several episodes of pulmonary and systemic emboli. Necropsy findings revealed non-obstructive cardiomyopathy. The heart was much enlarged, weighing $600 \mathrm{~g}$. Both right atrium and ventricle were extremely dilated. The tricuspid valve was dilated. No residual pulmonary valve stenosis was found. The left ventricle and atrium were moderately dilated. Thrombi were present in the right atrium, right ventricle, and left ventricle. The coronary arteries were normal. There were scars of infarcts in the kidneys and organized infarcts in the lower lobe of the right lung. Histologically, there was considerable hypertrophy of myocardial fibres of the left ventricle with extensive interstitial fibrosis.

Comment This I7-year-old youth suffered from congenital pulmonary stenosis. Non-obstructive cardiomyopathy was discovered at operation. The latter was confirmed at necropsy. Of interest is the presence of a sib suffering from non-obstructive cardiomyopathy.

\section{Results}

As shown in Table $I$, there were 7 female and 6 male patients. The patients ranged in age from 2 months to 37 years. The family history was pertinent in only 2 patients (Cases 4 and I3).

Of the I3 patients, I2 were symptomatic (Table 2). In 5 patients (Cases $6,7,8,10$, and I3) congestive heart failure was present and could not be explained by the congenital heart disease alone. The auscultatory findings, confirmed in 8 by phonocardiography, were dominated by those of the associated congenital heart diseases. Simultaneous carotid, jugular, and apex cardiograms were helpful in the diagnosis of cardiomyopathy. The typical form of the carotid pulse pressure curve of a short upstroke time, midsystolic dip, and late systolic rise was found in repeated studies in our patients with obstructive cardiomyopathy. The details of the findings in 3 patients (Cases $I, 6$, and $I I$ ) are shown in Fig. 2.

The electrocardiogram (Fig. I) revealed sinus rhythm in all. The mean QRS axis in the frontal plane ranged between $+90^{\circ}$ and

TABLE 2 Clinical data in 13 patients with cardiomyopathy associated with congenital heart disease

$\begin{array}{lr}\text { Asymptomatic } & \text { I } \\ \text { Dyspnoea } & 12 \\ \text { Congestive heart failure } & 6 \\ \text { Cyanosis } & 2 \\ \text { Thromboembolic phenomenon } & \text { I } \\ \text { Died } & 3\end{array}$

$+180^{\circ}$ in 6 , between $+90^{\circ}$ and 0 in 5 ; it was $-30^{\circ}$ in 1 , and undetermined in another. Other findings were as follows: $\mathbf{P}$ pulmonale in 2 , biatrial hypertrophy in $I$, right ventricular hypertrophy in 6, biventricular hypertrophy in 4, left ventricular hypertrophy in 1 ; in 2 patients (Cases 2 and 4 ) there were no definite signs of ventricular hypertrophy, but in one (Case 2) there were deep $Q$ waves in $V_{3}$ to V6. The electrocardiographic signs of left ventricular hypertrophy could be attributed to associated left-sided congenital heart defects other than cardiomyopathy in 7 patients (Cases 3, 4, 6, 7, 9, I1, and 12). In 6 (Cases I, 2, 5, 8, 10, and 13) the congenital defects did not explain the presence of left ventricular hypertrophy on the electrocardiogram and suggested the presence of cardiomyopathy as an associated disease.

The chest $x$-rays corresponded on the whole to the associated congenital heart defects. However, the presence of cardiomyopathy as an associated lesion was suggested in 5 patients (Cases I, 2, 8, I0, and I3) by $x$-ray evidence of left ventricular enlargement unexplained by the congenital heart defect itself.

Selective left ventriculograms were performed in ro patients and revealed the presence of classical features of obstructive cardiomyopathy in all. The size of the left ventricular cavity was reduced in all except one patient (Case 4). The free wall of the left ventricle was thickened. Different shapes of the left ventricular cavity were found, illustrative details of which are shown in Fig. 3, 4, 6 and 7.

In patients on whom continuous pressure tracings were recorded (Table $I$ ), a drop in systolic pressure occurred as the catheter was withdrawn from the left ventricular cavity through the outflow tract into the ascending aorta. This was due to the tip of catheter passing the region of the left ventricular outflow tract obstruction. Examples of these pressure recordings are given in Fig. 5 .

The details of the necropsy findings of the 3 patients (Cases I I, I2, and I3) are given in the respective case reports.

\section{Discussion}

There has been considerable speculation as to whether cardiomyopathy is a congenital or acquired form of heart disease. Some investigators (Braunwald et al., 1964) believe that both forms are possible. There is evidence that in some of the patients the condition may be inherited (Brent et al., 1960). Several authors (Keith, 1906, 1909, I924; Brachfeld and Gorlin, 196I) believe that some forms of obstructive cardiomyopathy are embryogenic 


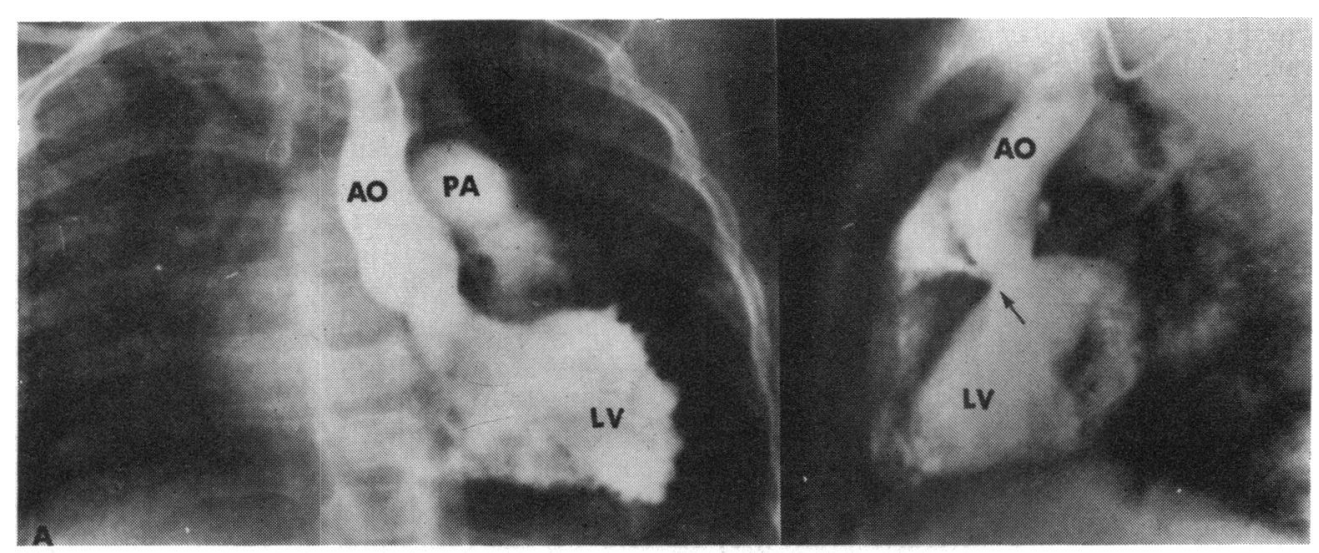

FIG. 7 ( $A$ and B.) Obstructive cardiomyopathy associated with parachute mitral valve complex, coarctation of the aorta, ventricular septal defect, mitral insufficiency, and peripheral pulmonary artery stenosis (Case 7). $A$ and $B$, left ventriculogram, frontal and lateral views, respectively, both in diastole. In $A$ irregular contour of the left ventricular cavity, and filling of the pulmonary artery by the left-to-right shunt (through the ventricular septal defect) are seen. In $B$ the ventricular septal defect (arrow) and the characteristic diastolic inverted cone, resulting from the encroachment of the hypertrophied interventricular septum on the one side and the anterior leaflet of the mitral valve from the other, are seen.

with persistence of the primitive bulbus cordis. According to them, the major portion of the bulbus cordis becomes incorporated in the right ventricular infundibulum as embryogenic growth progresses, while total atrophy of this tissue takes place in the left heart. Infundibular stenosis results from arrest of normal evolution of the bulbus on the right, and subaortic stenosis from its arrest on the left side of the heart.

Cases of obstructive cardiomyopathy appearing in many members of one family, lending support to the congenital aetiology of this disease, have been reported in the past (Brent et al., 1960). To these can be added our own 2 patients (Cases 3 and 4 ) who also presented the familial form of this condition.

Strong evidence to support the concept that obstructive cardiomyopathy may in some instances be a congenital anomaly was provided by the report of Neufeld, Ongley, and Edwards (1960). These authors presented detailed anatomical descriptions of two hearts showing obstructive cardiomyopathy, one in a stillborn infant and the other in a I-monthold baby. In support of this hypothesis, other authors (Daoud, Gallaher, and Kaplan, 196I ; Soulié, Joly, and Carlotti, r962; Wigle, Chrysohou, and Bigelow, 1963; Cohen et al., 1964; Braunwald et al., 1964) described patients in whom clinical, haemodynamic, and/or pathological evidence of the cardiomyopathy was present in early childhood.
In 9 of our patients the heart disease was discovered at birth and in 3 before the age of 3 months (Table I), again suggesting a congenital origin of the associated cardiomyopathy.

The developmental complex described by Shone et al. (1963) is of particular interest. This complex which has also been reported subsequently by others (Slezák et al., 1965; Simon, Friedman, and Roberts, 1969) comprises a parachute mitral valve deformity, coarctation of the aorta, supravalvular stenotic ring within the left atrium, and a subaortic stenosis. In reviewing these reports and our 3 patients (Cases 7, 9, and II), it appears that the obstructive cardiomyopathy is probably an integral part of the anomaly in the majority of cases. It seems scarcely conceivable that the presence of obstructive cardiomyopathy in these patients is a chance association and speaks strongly for a congenital origin of the cardiomyopathy.

The association of other congenital heart defects with obstructive cardiomyopathy provides additional evidence that some forms of cardiomyopathy may be congenital. Several authors (Davies, 1952; Beard, Cooley, and Latson, 1957; Lauer, DuShane, and Edwards, 1960; Walther, Madoff, and Zinner, 1960; Goodwin et al., 1961; Molthan, Paul, and Lev, 1962; McIntosh et al., 1962; Somerville and McDonald, I968) have reported this association. Furthermore, the fact that we 
have observed the presence of this association in 13 patients suggests that it is more frequent than hitherto suspected, and it may be that increased awareness towards this possibility may unearth additional cases.

In our experience, the presence of obstructive cardiomyopathy associated with a congenital heart defect should be suspected whenever the latter cannot explain one or more of the following: $I$ ) the presence of heart failure as in Cases 6,7,8, 10, and $13 ; 2$ ) unexpected degree of left ventricular hypertrophy in the electrocardiogram as in Cases $1,2,5,8$, and IO; 3) unexpected radiological signs of left ventricular hypertrophy as in Cases $1,2,8,10$ and 13 ; or 4 ) carotid pulse pressure curves and apex cardiogram suggesting obstructive cardiomyopathy as in Cases I, 2, 3, 4, 6, I0, and II.

\section{References}

Beard, E. F., Cooley, D. A., and Latson, J. R. (1957). Combined congenital subaortic stenosis and infundibular subpulmonic stenosis. Report of a case with successful surgical treatment. Archives of Internal Medicine, 100, 647.

Brachfeld, N., and Gorlin, R. (1959). Subaortic stenosis: a revised concept of the disease. Medicine, $3^{8}$, 415.

Brachfeld, N., and Gorlin, R. (196I). Functional subaortic stenosis. Annals of Internal Medicine, 54, I.

Braunwald, E., Lambrew, C. T., Rockoff, S. D., Ross, J., and Morrow, A. G. (1964). Idiopathic hypertrophic subaortic stenosis. I. A description of the disease based upon an analysis of 64 patients. Circulation, 30-31, Suppl. 4, 3.

Brent, L. B., Aburano, A., Fisher, D. L., Moran, T. J., Myers, J. D., and Taylor, W. J. (1960). Familial subaortic stenosis: An unrecognized form of 'idiopathic heart disease' with clinical and autopsy observations. Circulation, 21, 167.

Brock, R. (1957). Functional obstruction of the left ventricle. (Acquired aortic subvalvular stenosis.) Guy's Hospital Reports, 106, 221.

Cohen, J., Effat, H., Goodwin, J. F., Okley, C. M., and Steiner, R. E. (1964). Hypertrophic obstructive cardiomyopathy. British Heart fournal, 26, I6.

Daoud, G., Gallaher, M. E., and Kaplan, S. (I96I). Muscular subaortic stenosis. American fournal of Cardiology, 7, 860 .

Davies, L. G. (1952). A familial heart disease. British Heart fournal, 14, 206.
Goodwin, J. F., Gordon, H., Hollman, A., and Biship, M. B. (I96I). Clinical aspects of cardiomyopathy. British Medical fournal, 1, 69.

Keith, A. (1906). Malformations of the bulbus cordis an unrecognized division of the human heart. In Studies in Pathology, p. 55. Ed. by W. Bulloch. Aberdeen University Studies, No. 21.

Keith, A. (1909). Malformations of the heart (Hunterian Lectures). Lancet, 2, 359.

Keith, A. (1924). Fate of the bulbus cordis in the human heart. (Schorstein Lecture.) Lancet, 2, 1267.

Lauer, R. M., DuShane, J. W., and Edwards, J. E. (I960). Obstruction of left ventricular outlet in association with ventricular septal defect. Circulation, 22, 110.

McIntosh, H. D., Sealy, W. C., Whalen, R. E., Cohen, A. I., and Sumner, R. G. (I962). Obstruction to outflow tract of left ventricle. Archives of Internal Medicine, 110, 312.

Molthan, M. E., Paul, M. H., and Lev, M. (1962). Common A-V orifice with pulmonary valvular and hypertrophic subaortic stenosis. American fournal of Cardiology, ro, 291.

Neufeld, H. N., Ongley, P. A., and Edwards, J. E. (1960). Combined congenital subaortic stenosis and infundibular pulmonary stenosis. British Heart Fournal, 22, 686.

Shone, J. D. Sellers, R. D., Anderson, R. C., Adams, P., Jr., Lillehei, C. W., and Edwards, J. E. (1963). The developmental complex of 'parachute mitral valve', supravalvular ring of left atrium, subaortic stenosis, and coarctation of aorta. American fournal of Cardiology, 11, 714.

Simon, A. L., Friedman, W. F., and Roberts, W. C. (1969). The angiographic features of a case of parachute mitral valve. American Heart fournal, 77, 809.

Slezák, P., Steinhart, L., Procházka, J., Endrys, J., and Jurin, I. (1965). The angiographic appearances of subvalvar aortic stenosis. British fournal of Radiology, 38, 350.

Somerville, J., and McDonald, L. (1968). Congenital anomalies in the heart with hypertrophic cardiomyopathy. British Heart fournal, 30, 713.

Soulié, P., Joly, F., and Carlotti, J. (I962). Les sténoses idiopathiques de la chambre de chasse du ventricule gauche. Acta Cardiologica, 17, 335.

Walther, R. J., Madoff, I. M., and Zinner, K. (1960). Cardiomegaly of unknown cause occurring in a family. Report of three siblings and review of the literature. New England fournal of Medicine, 263, II04.

Wigle, E. D., Chrysohou, A., and Bigelow, W. G. (I963). Results of ventriculomyotomy in muscular subaortic stenosis. American fournal of Cardiology, II, 572 . 